\title{
Investigating environmental watering options using Source IMS: a case study - the River Murray, Australia
}

\author{
$\underline{\text { Md Jahangir Alam }^{a}}$, Alistair Korn ${ }^{\mathrm{b}}$ and Matthew Hardy \\ ${ }^{a}$ University of Southern Queensland, QLD 4350, Australia \\ ${ }^{b}$ Murray-Darling Basin Authority (MDBA), Canberra, ACT 2601, Australia \\ Email: Mdjahangir.Alam@usq.edu.edu
}

\begin{abstract}
The integrated modelling tool Source IMS developed by eWater and its partner organisations provides a common modelling platform to investigate the increasingly complex nature of water resources management in Australia. This paper describes how a recently built model of the River Murray using Source IMS has incorporated the management, delivery and accounting of water recovered for the environment to achieve required hydrological behavior. The River Murray model in Source IMS is fundamentally different from previous models of the River Murray in that it is run completely on a daily timestep, and has the capacity to run both as a planning model for policy development, and also as a daily operational tool used by River Operators to manage the competing demands for water in this complex system.
\end{abstract}

In the last few decades, there has been significant reform of water resources management in the MDB to address declining environmental condition within the Basin, including an increased focus on delivering water to environmental sites along the river system to achieve specific environmental outcomes. This paper shows how the Source model has been developed to investigate various environmental watering options in river systems planning. One of the major projects to recover water for the environment is The Living Murray (TLM), a joint partnership between the States of the River Murray to recover an average annual volume of $500 \mathrm{GL}$, to be used to deliver environmental outcomes at nominated icon sites along the river (MDBA, 2011). Icon sites were chosen for the high environmental and ecological values. Specified ecological objectives at each site dictate water requirements: the timing, frequency and magnitude of environmental diversions to the site. Two of the TLM icon sites the Koondrook-Perricoota forest and Hattah Lakes have been presented in this paper.

The ordering of water to the icon sites is accomplished through a Source Plugin; a dynamic-link library exposing purpose-built functionality to the Source River Murray project. This plugin triggers environmental watering events at the icon sites based on need and the volume of water available to the TLM.

The Resources Assessment functionality in Source undertakes allocation of water to TLM held entitlements over the simulation period. Due to the entitlements being held in a number of different allocation systems, triggers have been developed in Source IMS that transfer the TLM's available water from the State allocation systems to a TLM system to determine the total available water to the TLM. Individual use at each icon site is tracked across the model simulation, and the total use of TLM water is then accounted for in the State allocation systems based on an assumed priority of use.

During a simulation, the model records watering events at each icon site, either by overbank flow or TLM intervention. Once the elapsed time since the last flood exceeds the optimal inter-flood period, the model identifies a watering need at the icon site. During subsequent months, the model attempts to operate the works opportunistically, without placing an order but using flow that is not necessary to meet downstream demands. If the site was able to operate opportunistically for the first month, then it places a demand for subsequent months to complete the intervention. This type of intervention is termed an opportunistic watering. If a site's dry spell passes the resilience inter-flood period without starting opportunistically, then it registers a demand and initiates a forced watering. When watering needs exist at multiple sites, they are ranked according to need by a rostering algorithm.

The paper demonstrates how Source IMS has been able to model the complexity surrounding environmental watering in the River Murray. Further confirmation of the model's ability to represent the hydrological states of the TLM sites should make the model a useful tool when undertaking future work in environmental water planning and delivery on the River Murray.

Keywords: Environmental flow, water sharing, river operation, Source IMS, Murray-Darling Basin 


\section{INTRODUCTION}

The River Murray flows for 2,530 km through South-Eastern Australia and is the central river of the MurrayDarling Basin (Figure 1). The River Murray is managed and operated by the Murray-Darling Basin Authority (MDBA), who are responsible for regulating flow in the river through operating storages, weirs and regulators to deliver water to demands from water users along the river system as they require it.

The River Murray is operated to meet multiple, and often competing demands for water. These demands include water supply, irrigation, environmental protection and enhancement, cultural heritage, maintenance of water quality, navigation, recreation, tourism, hydro-power generation and flood mitigation. The MDBA also has the responsibility for sharing the water resources of the River Murray between the States of New South Wales, Victoria and South Australia as set out in the Murray-Darling Basin Agreement.

In the last few decades, there has been significant reform of water resources management in the MDB to address declining environmental condition within the Basin, including an increased focus on delivering water to sites along the river system to achieve specific environmental outcomes. Water reform has, and continues to add complexity to the operation and management of the river system, and for the last 50 years, the MDBA has used its hydrological modelling suite MSM-Bigmod to understand this complexity and inform: 1) Water resources planning, 2) The development and improvement of operating rules, 3) Auditing of major policy reforms in the MDB (Basin Salinity Management Strategy, Cap), 4) Accounting of

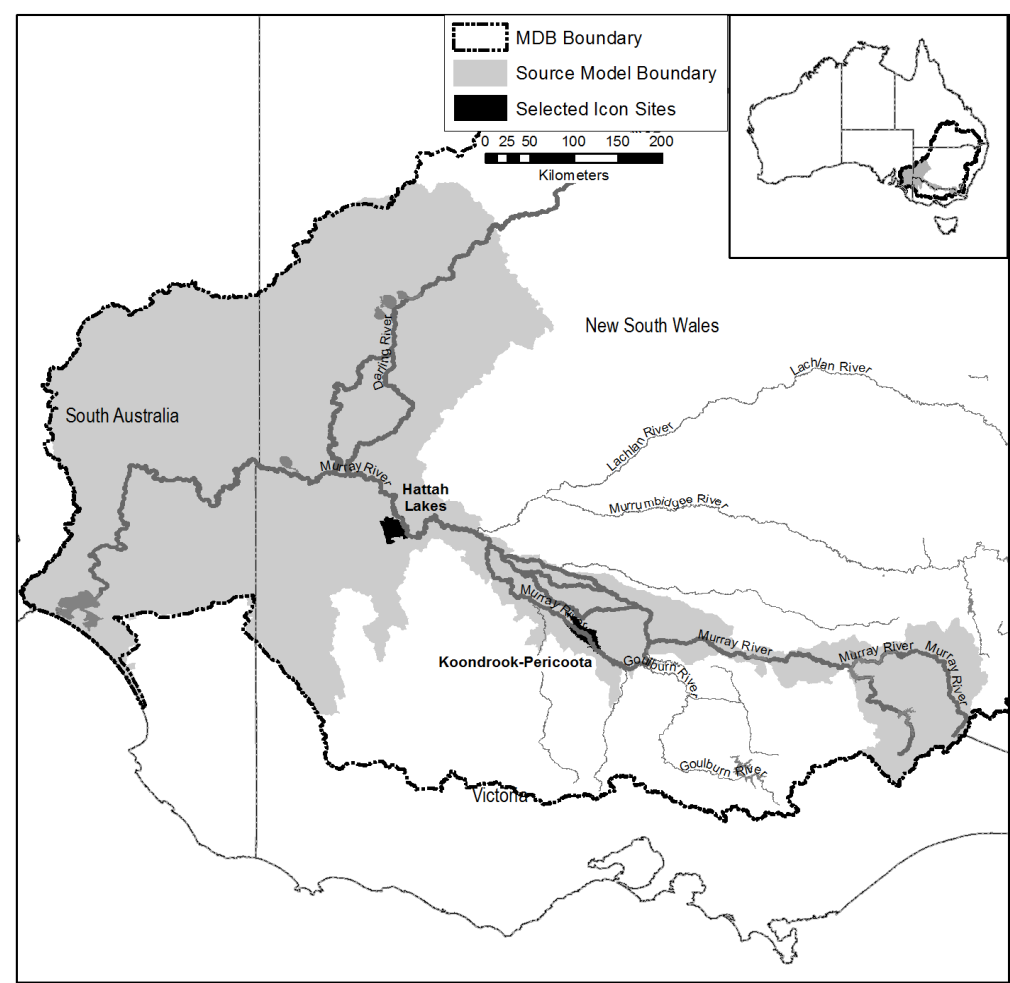

Figure 1. Map of River Murray including location of selected TLM sites. States' water shares, and 5) Flow and salinity forecasts. For each simulation, MSM models system operations on a monthly time step and then Bigmod routes the flow and salinity on a daily time step.

One of the major projects to recover water for the environment is The Living Murray (TLM), a joint partnership between the States of the River Murray to recover a long-term average annual volume of 500 GL, to be used to deliver environmental outcomes at nominated icon sites along the river (MDBA, 2011). Icon sites were chosen for the high environmental and ecological values. In recent years, these icon sites and their water demands have been incorporated in the MSM-Bigmod planning model, which makes monthly decisions on works operations. In MSM-Bigmod, environmental water is often used to augment minor natural events. As the field experience of environmental watering develops, there will be an increased interest in optimising the efficiency of the environmental entitlement portfolio. This will require planning and operations models that can respond to daily changes in system dynamics.

This paper describes how a recently-developed Source IMS model of the River Murray incorporates the management, delivery and accounting of water recovered under the TLM to achieve required hydrological behavior. The River Murray model in Source IMS is fundamentally different from MSM-Bigmod in that it is run completely on a daily timestep, and has the capacity to run both as a planning model for policy development, and also as a daily operational tool used by River Operators to manage the competing demands for water in this complex system. The hydrological representation of each icon site follows MSM-Bigmod, and is calibrated to hydraulic models of unregulated flood events. Recent commissioning of the various TLM structures will provide calibration datasets for further refinement of the hydraulic and hydrological models, including the Source IMS River Murray model. 


\section{OVERVIEW OF THE ENVIRONMENTAL DEMAND MODEL}

The River Murray model includes hydrologic representations of TLM icon sites. The ecological objectives at each site dictate water requirements: the timing, frequency and magnitude of environmental diversions to the site. Two of the TLM icon sites have been presented in this paper. An overview of these selected icon sites is given below in downstream order.

The Koondrook-Perricoota forest adjoins the NSW bank of the River Murray between Torrumbarry Weir and Barham. There are three nested watering demands, listed from lowest to highest:

1. A wetland watering of $2000 \mathrm{ML} /$ day for 42 days;

2. A bird-breeding event of $2000 \mathrm{ML} /$ day for 33 days, followed by $500 \mathrm{ML} / \mathrm{d}$ for a further 70 days;

3. A full-forest watering of up to $6,000 \mathrm{ML} /$ day for a period of 105 days.

The water is held against a downstream levee, and outflow from Koondrook-Perricoota forest is regulated at three places. The Thule Creek and Barbers Creek regulators release water to the Wakool River, while the Return Channel returns water to the River Murray at up to 1,850 ML/day.

The Hattah Lakes icon site comprises an interconnected system of thirteen lakes. An environmental watering may be initiated by pumping $500 \mathrm{ML} /$ day to Lake Lockie via Chalka Creek to achieve a target level of 43.5 $\mathrm{m}$ AHD at the North Chalka regulator. In addition, inflow from an unregulated flow event may be augmented with pumping up to $1,000 \mathrm{ML} /$ day, to achieve a target water level of $45.0 \mathrm{~m}$ AHD.

\subsection{Available Water to the TLM}

Allocation of water to TLM held entitlements is undertaken in the Resource Assessment functionality in Source IMS. Table 1 lists the allocation systems where TLM entitlements are held. The total volume of shares is greater than the long-term average recovered volume of $500 \mathrm{GL}$, however reliability of supply to the various entitlements results in an average annual volume of approximately $500 \mathrm{GL}$ being allocated to the TLM over the simulation period. Due to the entitlements being held in a number of different allocation systems, triggers have been developed in Source IMS that transfers the TLM's available water from the State allocation systems to a TLM allocation system to determine the total available water to the TLM. Individual use at each icon site is tracked across the model simulation, and the total use of TLM water is then accounted for in the State allocation systems based on an assumed priority of use, listed in Table 1, with priority 1 being the highest priority use. The priorities assume that the TLM will use the available water in priority from the least reliable water entitlements to the most reliable water entitlements.

Table 1. Volumes of held TLM Water Entitlements.

\begin{tabular}{|l|l|c|}
\hline System & Account Type & Priority \\
\hline Vic Murray & TLM Off-allocation & 1 \\
\hline Goulburn & Goulburn High Reliability Water Share Extended Carryover (carryover component) & 2 \\
\hline Goulburn & Campaspe High Reliability Water Share Extended Carryover (carryover component) & 2 \\
\hline Vic Murray & High Reliability Water Share Extended Carryover (carryover component) & 2 \\
\hline Goulburn & Goulburn Low Reliability Water Share Extended Carryover (carryover component) & 3 \\
\hline Goulburn & Campaspe Low Reliability Water Share Extended Carryover (carryover component) & 3 \\
\hline Vic Murray & Low Reliability Water Share Extended Carryover & 3 \\
\hline RMIF & Hume Account (carryover component) & 4 \\
\hline Murrumbidgee & General Security & 5 \\
\hline NSW Murray & High Security & 5 \\
\hline NSW Murray & General Security & 5 \\
\hline SA Murray & SA Entitlement & 5 \\
\hline Lower Darling & High Security & 5 \\
\hline Lower Darling & General Security & 5 \\
\hline Goulburn & Goulburn High Reliability Water Share Extended Carryover & 6 \\
\hline Vic Murray & High Reliability Water Share Extended Carryover & 6 \\
\hline Goulburn & High Reliability Water Share & 7 \\
\hline Goulburn & Low Reliability Water Share & 7 \\
\hline Vic Murray & High Reliability Water Share & 7 \\
\hline Goulburn & Goulburn Low Reliability Water Share Extended Carryover & 8 \\
\hline Goulburn & Campaspe High Reliability Water Share Extended Carryover & 8 \\
\hline Goulburn & Campaspe Low Reliability Water Share Extended Carryover & 8 \\
\hline Vic Murray & Low Reliability Water Share Extended Carryover & 8 \\
\hline RMIF & Hume Account & 9 \\
\hline
\end{tabular}




\subsection{Ordering and Rostering}

The ordering of water to the icon sites is accomplished through a Source Plugin; a dynamic-link library exposing purpose-built functionality to the Source River Murray project. This plugin triggers environmental watering events at the icon sites, based on need and the volume of water available to the TLM.

For each TLM icon site, an environmental watering demand is calculated on the basis of various pre-defined parameters:

- Volume requirements (i.e. flow threshold and duration),

- Optimal inter-flood period, describing the period for which healthy ecological conditions are maintained after a watering,

- Resilience inter-flood period, describing the maximum period that ecological conditions can be sustained without watering and

- Equivalent Flows at the river that achieve the proposed operating strategies by overbank flows.

During a simulation, the model records watering events at each icon site, either by overbank flow or TLM intervention. Once the elapsed time since the last flood exceeds the optimal inter-flood period, the model identifies a watering need at the icon site. During subsequent months, the model attempts to operate the works opportunistically, without placing an order but using surplus flow in the system. If the site was able to operate opportunistically for the first month, then it places a demand for subsequent months to complete the intervention. This type of intervention is termed an opportunistic watering. If a site's dry spell passes the resilience inter-flood period without starting opportunistically, then it registers a demand and initiates a forced watering. When watering needs exist at multiple sites and there is limited water available to the TLM, the sites are ranked according to need by a rostering algorithm. The scheduling and rostering process is illustrated in Figure 2.

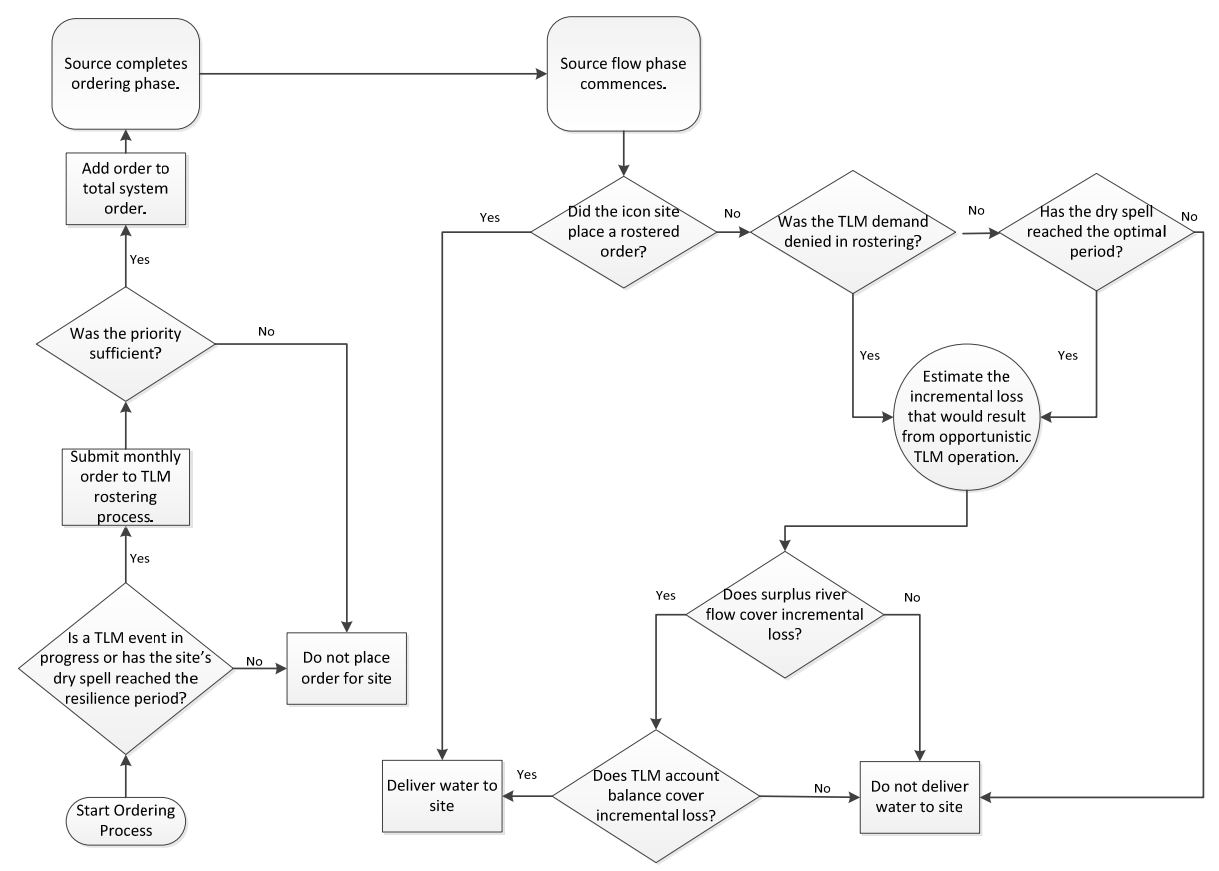

Figure 2. The scheduling and rostering process for operating TLM icon sites.

\subsection{Koondrook-Perricoota Forest icon site}

The representation of the Koondrook forest TLM icon site is shown in Figure 3. The model is calibrated on the basis of hydraulic modelling studies (Tuteja \& Shaikh (2009), MDBA (2011a) and MDBA (2012a)). The inlet regulator takes up to $6,000 \mathrm{ML} /$ day from Torrumbarry weir pool. This TLM diversion can either be ordered, or diverted opportunistically from any surplus flow. The TLM flow requirement may also be met from overbank flow downstream of Torrumbarry Weir. During fully-managed TLM events; in which all inflow is fully regulated, the Thule Creek regulator is closed, while the Barbers Creek regulator releases water at a nominal rate of $400 \mathrm{ML} /$ day, based on downstream capacity in the Barbers Creek system. At forest inflows of $6,000 \mathrm{ML} / \mathrm{day}$, the Return Channel intercepts approximately $600 \mathrm{ML} / \mathrm{day}$. As the water level against the downstream levee increases, the Murray Return Channel is further engaged and increases to a regulated maximum of $1,850 \mathrm{ML} /$ day. Thus, the Return Channel provides a means of maintaining the 
ecologically beneficial inflow of $6,000 \mathrm{ML} /$ day longer than would otherwise be possible given the 400 ML/day release constraint at Barbers Creek. To capture these modes of Return Channel engagement, there are two links in the model.

The operation of the downstream structures seeks to pass unregulated flow events unimpeded. Thus, during periods of both managed and unmanaged inflow, the Thule Creek regulator is opened according to the ratio of unmanaged-to-managed inflow. Similarly, at the Barbers Creek regulator, the overbank inflow is lagrouted through to Barbers Creek, and released through the regulator. On the other hand, unregulated forest inflow entails a higher level in the River Murray, thus reducing the efficacy of the Return Channel.

\section{a) Koondrook- Perricoota Site}

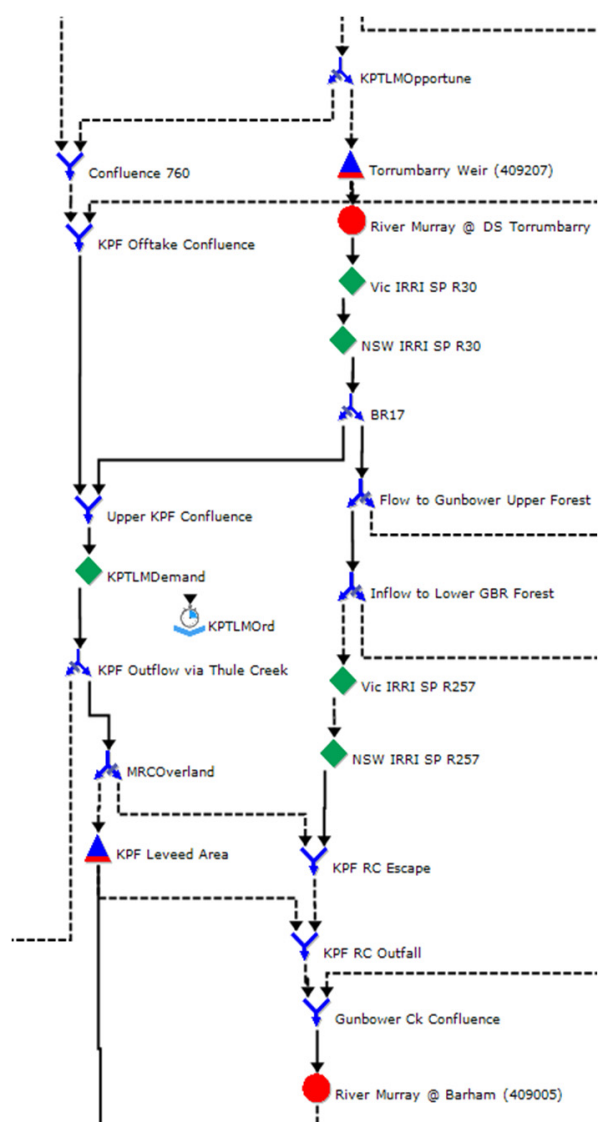

b) Hattah Lakes Site

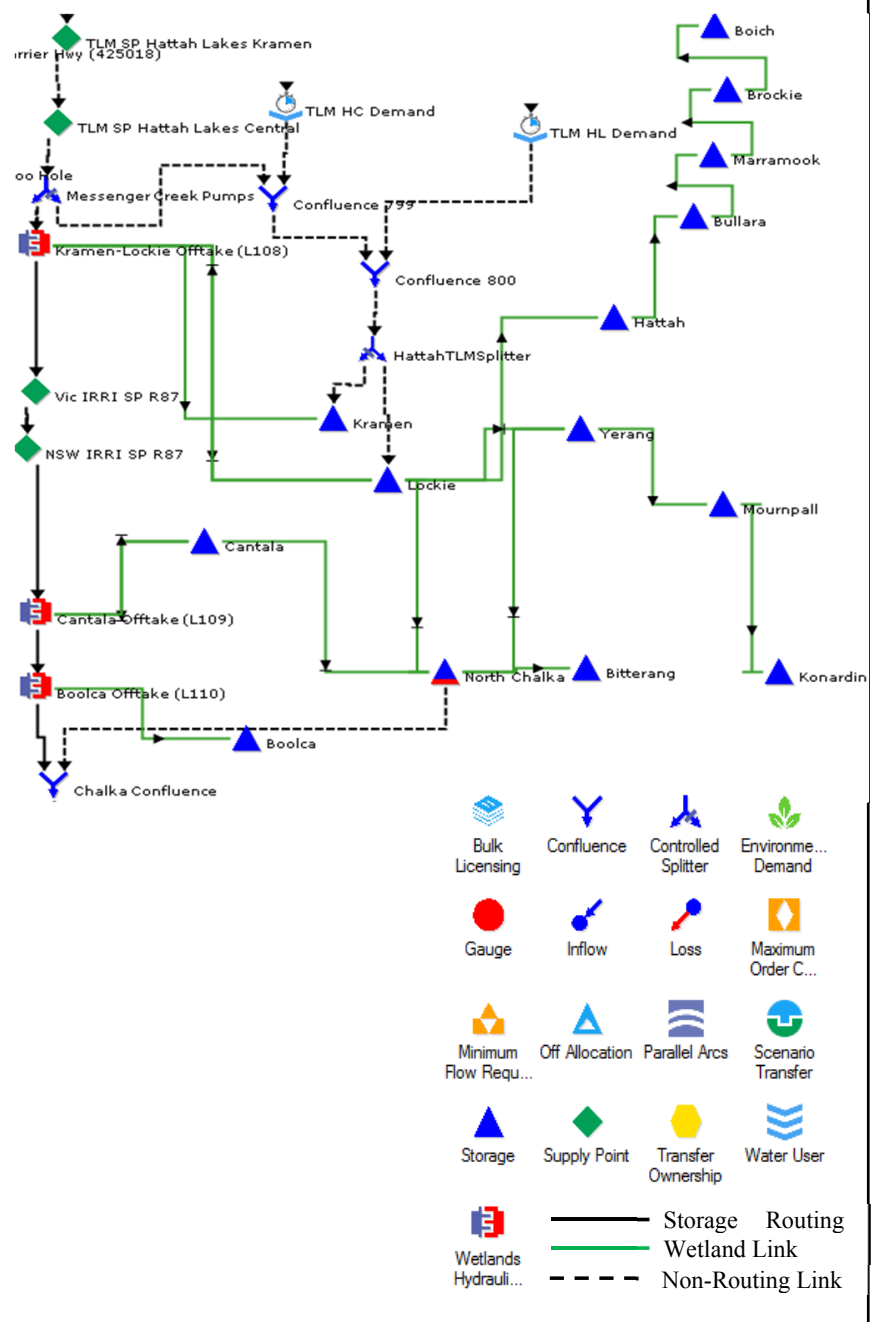

Figure 3. Model schematics of selected TLM icon sites.

\subsection{Hattah Lakes Icon Site}

The representation of Hattah Lakes in the River Murray Source model is shown in Figure 3. The lake system receives unregulated inflow to Lakes Lockie, Cantala and Boolca. The channel bed of Chalka Creek has been lowered as part of TLM works and measures program to increase the frequency of natural inflows. In addition a permanent pump station has been set up to deliver water to Lake Kramen and Chalka Creek when flow in the river is not sufficient to engage Chalka Creek. Operation of the North Chalka weir allows water to be retained in the system to increase the duration of natural flood events and enable water to be pumped into the outer lakes to water red gum and black box trees at higher elevations. This conceptualisation follows the MSM-Bigmod representation, described by Lee, Sharma \& Close (2009). 


\section{RESULTS AND DISCUSSIONS}

The River Murray model was run for the simulation period July 1895- June 2009. During this period, the TLM icon sites place water demands, which are rostered against the available environmental water. This section presents examples of TLM diversion at Koondrook-Perricoota Forest and Hattah Lakes. We also show how water is accounted to the different accounting systems at an event in Koondrook-Perricoota Forest.

In Figure 4 we show the site inflow and outflow during an environmental flow event. For reference the main stem flow at the Torrumbarry gauge is also shown. This is a hybrid event, with both managed TLM diversion and unmanaged overbank inflow. There are three Torrumbarry flow peaks, labelled (a) - (c). As the TLM diversion flows through the forest, the Return Channel engages and the Barbers Creek regulators release $400 \mathrm{ML} /$ day. The subsequent river peaks

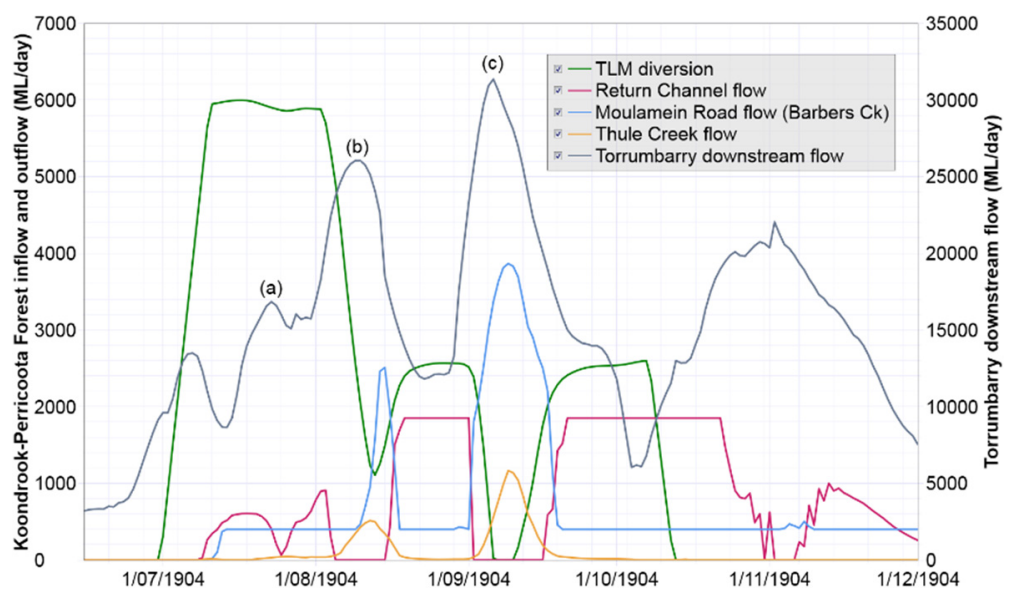

Figure 4. Koondrook-Perricoota Forest operations during a hybrid TLM event. impact each of the forest inlets and outlets. The forest's environmental demand is partially met by overbank inflow, and the TLM diversion reduces accordingly. The rising river level reduces the capacity of the Return Channel, which stops flowing. The overbank peaks are lag-routed through the forest and, in the case of (b) and (c), produce flow pulses at the Thule Creek and Barbers Creek outlets.

The Hattah Lakes pumping scheme operates at $500 \mathrm{ML} /$ day for a maximum duration of 91 days. During a pumping operation, the North Chalka water level is monitored and pumping ceases at a target level of $43.5 \mathrm{~m}$ AHD. In Figure 5 we show two pumping operations. The first operation is accompanied by a significant flow event in the River Murray. The North Chalka regulator level reaches target after 35 days. Two years

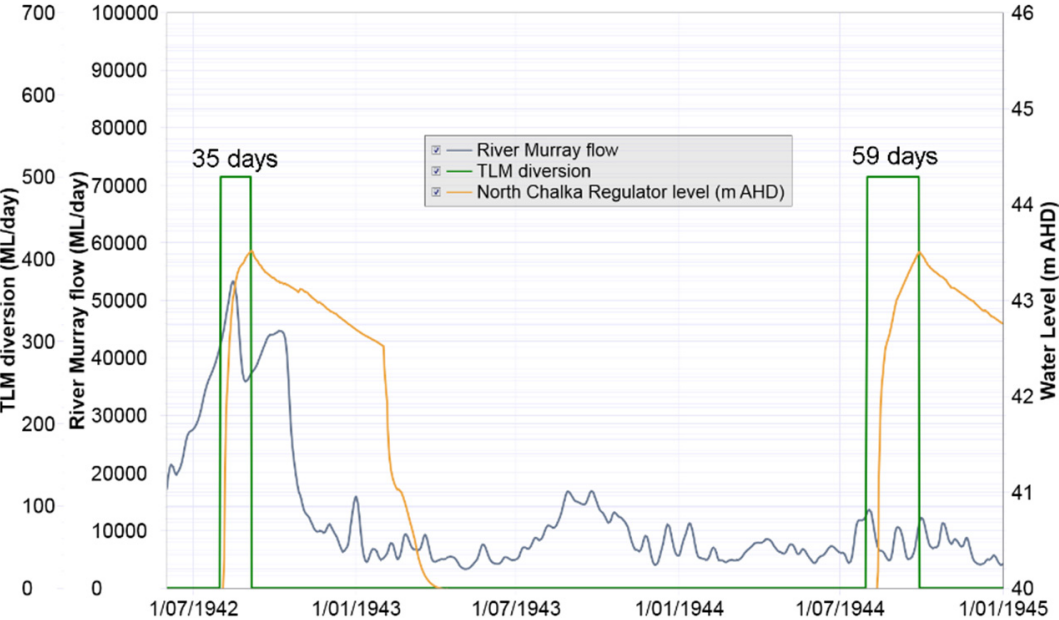

Figure 5. Operation of Hattah Lakes pumping. later, with no intervening River Murray flow events, a pumping operation is again initiated. In the absence of unregulated inflow from the River Murray, the achievement of the target level requires 59 days of pumping.

Figure 6 shows the TLM account usage of a Koondrook-Perricoota forest event, and the prioritisation of TLM use to the different water accounts in accordance with Table 1. At the start of the event an offallocation event on the River Murray is occurring, so the TLM initially utilises its available account balance of TLM off-allocation water (the highest priority in Table 1). Once the available off-allocation water begins to decline, the site begins to debit accounts in the Goulburn and Victorian Murray allocation systems. 


\section{CONCLUSIONS}

The management of environmental watering at the icon sites has been simulated successfully using Source IMS. This has been achieved through a Source Plugin that keeps track of watering events, triggers demands based on needs and prioritises competing environmental demands at multiple TLM icon sites through a rostering algorithm. The rostering algorithm takes into account; the elapsed time since their last watering, the total requirements to meet specified environmental

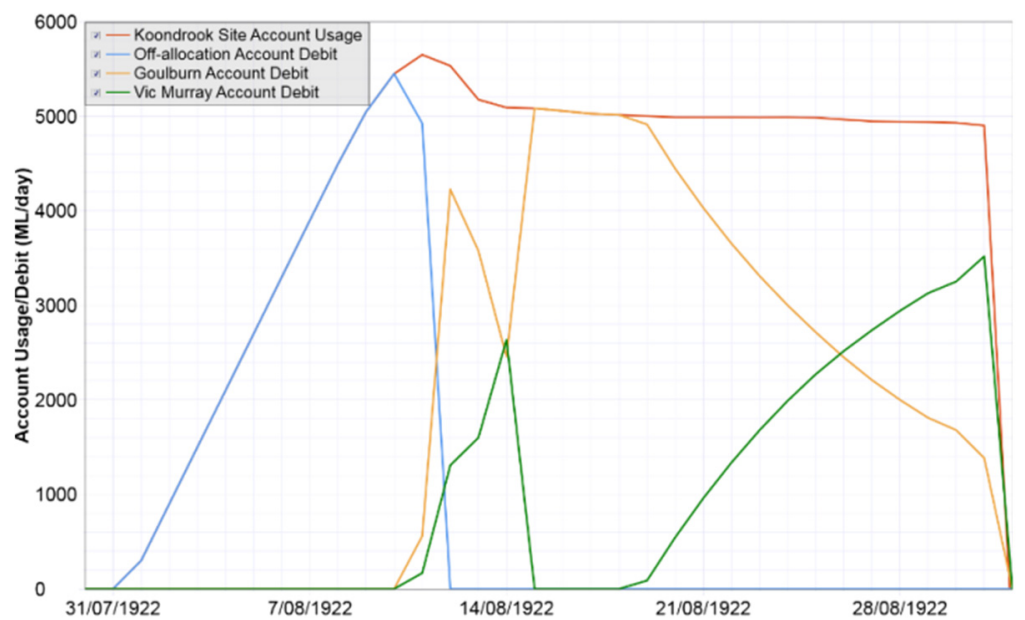

Figure 6. Accounted use for a Koondrook-Perricoota Forest Event. objectives, the total volume of water allocated to TLM and their capacity to utilise surplus flow in the system. The water used to undertake environmental watering at the icon sites is then tracked using the accounting system in Source IMS to analyse the use of entitlements to deliver environmental outcomes. Demonstration of how the plugin interacts with the Source IMS model of the River Murray has been shown for two TLM icon sites; Koondrook-Perricoota Forest and Hattah Lakes.

Source IMS has proved to be an effective and transparent tool to undertake the work in this paper. The model schematic has allowed greater communication of the hydrological representation of TLM sites in the model, and the relative ease of modifying and altering the model structure has helped in testing the complexity of the plugin. The capacity to modify and alter model behavior will be a considerable asset when undertaking future work in environmental water delivery for the River Murray. In addition the ability to run the model in an operational mode will allow the functionality used for policy development of environmental water delivery to potentially also form the basis of daily operational decisions in delivering environmental water.

\section{ACKNOWLEDGEMENTS}

The authors greatly acknowledge the contribution of members of the Water Resource Group from the Murray-Darling Basin Authority (MDBA) in contributing to the work reported on in this paper. This study is part of the project on implementing a Source IMS model of the River Murray-Lower Darling system.

\section{REFERENCES}

Lee, J., Sharma, P., \& Close, A. (2009). Hydrological modelling of the Hattah Lakes system - Extension of the Commission's water resources models and assessment of TLM structural options,. Canberra: Murray-Darling Basin Commission.

MDBA. (2011a). Hydrodynamic Modelling to Support KPF flood enhancement operations. Canberra: MDBA.

MDBA. (2011b). The Living Murray Program. Fact Sheet: Reference 29/11. Canberra.

MDBA. (2012a). Calibration of a hydraulic model between Torrumbarry and Barham. Canberra.

MDBA. (2012b). Hattah Lakes: Environmental Water Management Plan. Canberra: Murray-Darling Basin Authority (MDBA).

MDBC. (2005). The Living Murray Foundation Report on the significant ecological assets targeted in the first step decision making. Canberra: MDBC Publication No. 09/05.

Tuteja, N., \& Shaikh, M. (2009). Hydraulic Modelling of the spatio-temporal flood inundation patterns of the Koondrook-Perricoota Forest Wetlands. 18th World IMACS MODSIM Congress, (pp. 4248-4254). Cairns. 